3 Kraemer MJ, Richardson MA, Weiss NS, et al. Risk factors for persisten middle ear effusions: otitis media, catarrh, cigarette smoke exposure and atopy. FAMA 1983;249: 1022-5.

4 Black N. The aetiology of glue ear-a case-control study. Int $\mathcal{f}$ Pediat Otorhinolaryngol 1985;9:121-33.

Hinton AE, Buckley G. Parental smoking and middle ear effusions in children. f Laryngol Otol 1988;102:992-6.

6 Black N. "Health culture" of families as an influence on the use of surgery for glue ear: a case-control study. Int $\mathcal{f}$ Epidemiol 1985;14:594-9.

Black N. Geographical variations in the use of surgery for glue ear. $7 R$ Soc Med 1985:78:641-8.

8 Iversen $M$, Birch L, Lundqvist GR, Elbrond O. Middle ear effusion and the indoor environment. Arch Environ Health 1985;40:74-9.

9 Vintner B, Elbrond O, Brahe Pedersen C. A population study of otitis media in childhood. Acta Otolaryngol [Suppl] (Stockh) 1979;360:121-3.

10 van Cauwenberge $P B$. Relevant and irrelevant predisposing factors in secretory otitis media. Acta Otolaryngol [Suppl](Stockh) 1984;414:147-53.

11 Birch L, Elbrond $O$. A prospective epidemiological study of secretory otitis media in young children related to the indoor environment. $O R L \mathcal{J}$ Otorhinolaryngol Relat Spec 1987;49:253-8.

12 Zielhus GA, Rach GH, van den Broek P. Predisposing factors for otitis media with effusion in young children. Adv Otorhinolaryngol 1988;40:65-9.

13 Brooks DN. An objective method of detecting fluid in the middle ear International Audiology 1968;7:280-6.

14 Fria TJ, Cantekin EI, Probst G. Validation of an automatic otoadmittance middle ear analyzer. Ann Otol Rhinol Laryngol 1980;89:253-6.

15 Fiellau-Nikolajsen M. Tympanometry and secretory otitis media. Acto Otolaryngol [Suppl] (Stockh) 1983;394:1-73.

16 Feyerabend C, Bryant AE, Jarvis MJ, Russell MAH. Determination of cotinine in biological fluids of non-smokers by packed column gas-liquid colno in

17 Jarvis $M$, Tunstall-Pedoe H, Feyerabend C, Vesey C, Saloojee Y. Biochemical markers of smoke absorption and self-reported exposure to passive smoking. I Epidemiol Community Health 1984;38:335-9.

18 Jarvis MJ, Tunstall-Pedoe H, Feyerabend C, Vesey C, Saloojee Y. Comparison of test used to distinguish smokers from nonsmokers. Am f Public Health

19 Jarvis MJ, Russell MAH, Feyerabend C, et al. Passive exposure to tobacco smoke: saliva cotinine concentrations in a representative population sample of non-smoking schoolchildren. Br Med $\mathcal{F}$ 1985;291:927-9

20 McNeill AD, Jarvis MJ, West R, Russell MAH, Bryant A. Saliva cotinine as an indicator of cigarette smoking in adolescents. Br $\mathcal{F}$ Addict 1987;82:1355-60.

21 Strachan DP. Damp housing and childhood asthma: validation of symptom reporting. Br Med f 1988;297:1223-6.

22 Office of Population Censuses and Surveys. Classification of occupations and coding index. London: HMSO, 1980.

23 Jerger J. Clinical experience with impedance audiometry. Archives of Otolaryngology 1970;92:311-24.

24 SAS Institute. SAS user's guide: basics. Version 5. Cary, North Carolina: SAS Institute, 1985 .

25 SAS Institute. SAS user's guide: statistics. Version 5. Cary, North Carolina: SAS Institute, 1985.

26 Baker RJ, Nelder JA. The GLIM system manual (release 3). Oxford:Numerical Algorithms Group, 1978 .

27 Mantel N. Chi-square tests on one degree of freedom: extensions of the Mantel-Haenszel procedure. Journal of the American Statistical Association 1963;58:690-700

28 Portoian-Shuhaiber S, Cullinan TR. Middle ear disease assessed by impedance in primary school children in south London. Lancet $1984 ; \mathrm{i}: 1111-2$.

29 Lous J, Fiellau-Nikolajsen M. Epidemiology of middle ear effusion and tuba dysfunction. A one-year prospective study comprising monthly tympanometry in 387 non-selected 7-year-old children. Int f Pediatr Otorhinolaryngol 1981;3:303-17.

30 Jarvis $M J$, McNeill AD, Russell MAH, West RJ, Bryant A, Feyerabend C. Passive smoking in adolescents: one-year stability of exposure in the home. Lancet 1987;i:1324-5.

31 Cochran WG. Errors of measurement in statistics. Technometrics 1968;10:637 66.

32 Maw AR. Otitis media with effusion (glue ear). In: Kerr AG, Groves J, Evan NG, eds. Scott-Brown's otolaryngology. Sth ed. Vol 6. London: Butterworths, 1987:159-76.

33 Etzel RA. Smoke and ear effusions. Pediatrics 1987;79:309-10.

34 Maran AGD, Wilson JA. Glue ear and speech development. Br Med $\mathcal{J}$ $1986 ; 293: 713-4$

(Accepted 5 April 1989)

\title{
Relation between mortality and treated blood pressure in elderly patients with hypertension: report of the European Working Party on High Blood Pressure in the Elderly
}

\author{
J Staessen, C Bulpitt, D Clement, P De Leeuw, R Fagard, A Fletcher, F Forette, G Leonetti, \\ A Nissinen, K O'Malley, J Tuomilehto, J Webster, B O Williams
}

\section{Abstract}

Objective-To investigate the relation between mortality and treated systolic and diastolic blood pressures.

Design-Randomised double blind placebo controlled trial. Mortality in the two treatment groups was examined in thirds of treated systolic and diastolic blood pressures.

Patients-339 And 352 patients allocated to placebo and active treatment, respectively. The groups were similar at randomisation in sex ratio ( $70 \%$ women), mean age $(71.5$ years), blood pressure $(182 / 101 \mathrm{~mm} \mathrm{Hg})$, and proportion of patients with cardiovascular complications (35\%).

Measurements and main results-In the placebo group total mortality rose with increasing systolic pressure whereas it had a $U$ shaped relation with diastolic pressure, the total lowest mortality being in patients in the middle third of the distribution of diastolic pressure. In the group given active treatment total mortality showed a $U$ shaped relation with systolic pressure and an inverse association with treated diastolic pressure. In both groups cardiovascular and non-cardiovascular mortality followed the same trends as total mortality. The increased mortality in the lowest thirds of pressure was not associated with an increased proportion of patients with cardiovascular complications at randomisation or with a fall in diastolic pressure exceeding the median fall in pressure in each group. In contrast, patients in the lowest thirds of pressure showed greater decreases in body weight and haemoglobin concentration than those in the middle and upper thirds of pressure.
Conclusions - In patients taking active treatment total mortality was increased in the lowest thirds of treated systolic and diastolic blood pressures. This increased mortality is not necessarily explained by an exaggerated reduction in pressure induced by drugs as for diastolic pressure a $U$ shaped relation also existed during treatment with placebo. In addition, patients in the lowest thirds of systolic and diastolic pressures were characterised by decreases in body weight and haemoglobin concentration, and the patients in the lowest thirds of diastolic pressure taking active treatment also by an increased non-cardiovascular mortality, suggesting some deterioration of general health.

\section{Introduction}

Several large studies of hypertension have recently been reviewed. ${ }^{12}$ The observation in these studies of a $J$ shaped relation between the risk of myocardial infarction and treated blood pressure ${ }^{3-9}$ has led to the suggestion that a reduction of pressure induced by drugs might cause as well as prevent myocardial ischaemia. ${ }^{1011}$ None of the studies was placebo controlled, and other large hypertension-mortality intervention trials have either not confirmed ${ }^{12-14}$ or not reported ${ }^{15}{ }^{16}$ this $\mathrm{J}$ shaped relation. In the international prospective primary prevention study in hypertension all patients received active drugs but patients with overt ischaemic heart disease were excluded ${ }^{14}$; there was no evidence for a J curve. In contrast, Coope and Warrender found that total mortality and deaths from myocardial infarction showed a J shaped relation with the diastolic pressure attained in elderly patients with

Hospital Gasthuisberg, 
hypertension taking active treatment as well as in untreated controls. ${ }^{1718}$

The present paper is based on the results of the trial conducted by the European Working Party on High Blood Pressure in the Elderly. ${ }^{19-21}$ The trial comprised elderly patients with hypertension randomly allocated to placebo or active treatment. We studied the mortality in the patients, who were grouped in thirds of the distribution of treated blood pressure. In addition, the presence of cardiovascular complications at randomisation, the fall in diastolic pressure after randomisation, and some variables of general health, such as haemoglobin concentration and body weight, were examined as possible correlates of mortality.

\section{Patients and methods}

Study protocol-At entry to the trial all patients were aged $\geqslant 60$ and had a sitting blood pressure when taking placebo during a run in period of 160-239/90-119 mm Hg. After stratification for sex, age, and the presence or absence of cardiovascular complications, 840 patients were randomised either to active treatment (hydrochlorothiazide and triamterene) or to matching placebo. If blood pressure remained high methyldopa was added to the active regimen and matching placebo in the control group. Full details of the protocol have been published. ${ }^{19}$

Statistical methods-Mortality was related to the blood pressure during randomised treatment (perprotocol analysis). ${ }^{19}$ For reasons discussed below treated blood pressure was defined as the blood pressure at nine months of follow up. In the two treatment groups patients were subdivided into thirds by the 33rd and 66th centiles of their treated systolic and diastolic pressures. The centile boundaries are indicated by the term tertiles. Mortality in the thirds of treated pressure was adjusted for age and sex by the direct method $^{22}$ and compared in two tailed tests by calculating standard deviations. We used Student's $t$ test to compare means.

\section{Results}

PATIENTS

Eighty five of the 424 patients randomised to placebo and 64 of the 416 patients randomised to active treatment left the study before the follow up visit at nine months; these patients were therefore not included in the present analyses. Of those excluded, 24 patients in the placebo group and 17 of those taking active treatment had died. Thus the analyses were of 339 patients randomised to placebo and 352 patients randomised to active treatment, and the number of patient years of observation were 1211 and 1351, respectively. The two groups analysed were similar at randomisation in sex ratio (nearly $70 \%$ women), mean age (71.5 years), systolic ( $182 \mathrm{~mm} \mathrm{Hg}$ ) and diastolic $(101 \mathrm{~mm} \mathrm{Hg})$ blood pressures, and proportion of patients with cardiovascular complications (nearly $35 \%$ ).

Tables I and II show the characteristics of the patients by thirds of treated systolic and diastolic blood pressures respectively. The ranges of blood pressure show that active treatment produced a shift in systolic and diastolic blood pressures. Indeed, blood pressure was similar in the lowest and middle thirds of the placebo and active treatment groups, respectively. Treated pressure was similar in the middle third of the group taking placebo and the highest third of the group taking active treatment.

TABLE I-Characteristics of patients according to treatment and thirds of treated systolic pressure

\begin{tabular}{|c|c|c|c|c|c|c|}
\hline & \multicolumn{3}{|c|}{ Placebo group } & \multicolumn{3}{|c|}{ Active treatment group } \\
\hline & $\begin{array}{c}\text { Lowest } \\
\text { third } \\
(n=121)\end{array}$ & $\begin{array}{c}\text { Middle } \\
\text { third } \\
(n=113)\end{array}$ & $\begin{array}{c}\text { Highest } \\
\text { third } \\
(n=105)\end{array}$ & $\begin{array}{c}\text { Lowest } \\
\text { third } \\
(n=120)\end{array}$ & $\begin{array}{c}\text { Middle } \\
\text { third } \\
(n=126)\end{array}$ & $\begin{array}{c}\text { Highest } \\
\text { third } \\
(n=106)\end{array}$ \\
\hline No of person years of follow up in double blind study & 473 & 422 & 316 & 476 & 487 & 388 \\
\hline No $(\%)$ men at randomisation & $42(35)$ & $37(33)$ & $21(20)$ & $38(32)$ & $37(29)$ & $31(29)$ \\
\hline No $(\%)$ with cardiovascular complications at randomisation & $36(30)$ & $47(42)$ & $32(30)$ & $36(30)$ & $47(37)$ & $42(40)$ \\
\hline No $(\%)$ who smoked at randomisation & $17(14)$ & $20(18)$ & $11(10)$ & $29(24)$ & $26(21)$ & $13(12)$ \\
\hline Mean (SD) age at randomisation (years) & $72 \cdot 3(7 \cdot 7)$ & $70 \cdot 2(7 \cdot 4)$ & $72 \cdot 5(8 \cdot 2)$ & $71 \cdot 6(8 \cdot 8)$ & $71 \cdot 0(7 \cdot 9)$ & $71 \cdot 7(7 \cdot 2)$ \\
\hline \multicolumn{7}{|c|}{ Characteristics during follow up } \\
\hline Extremes of treated systolic pressure $(\mathrm{mm} \mathrm{Hg})$ & $124-162$ & $164-180$ & $182-244$ & $100-144$ & $146-158$ & $160-236$ \\
\hline Treated systolic/diastolic pressure at middle of third $(\mathrm{mm} \mathrm{Hg})$ & $151 / 88$ & $172 / 97$ & $201 / 104$ & $134 / 84$ & $152 / 88$ & $172 / 92$ \\
\hline \multicolumn{7}{|l|}{$\begin{array}{l}\text { Mean (SD) difference between treated pressure and pressure at } \\
\text { randomisation }(\mathrm{mm} \mathrm{Hg}) \text { : }\end{array}$} \\
\hline Systolic & $-24(15)$ & $-7(15)$ & $9(17)$ & $-44(18)$ & $-29(16)$ & $-17(19)$ \\
\hline Diastolic & $-11(9)$ & $-3(9)$ & $1(11)$ & $-16(9)$ & $-13(8)$ & $-9(11)$ \\
\hline Mean (SD) body weight at 9 months $(\mathrm{kg})$ & $65.2(13.9)$ & $68.6(13.4)$ & $66 \cdot 6(12 \cdot 4)$ & $64 \cdot 5(12 \cdot 7)$ & $65.8(11.7)$ & $66 \cdot 9(12 \cdot 0)$ \\
\hline Mean (SD) haemoglobin at 1 year $(\mathrm{g} / \mathrm{l})$ & $140(14)$ & $142(15)$ & $146(15)$ & $139(15)$ & $141(16)$ & $142(18)$ \\
\hline No of patients in whom haemoglobin was measured & 91 & 90 & 77 & 91 & 87 & 92 \\
\hline
\end{tabular}

ॠTreated systolic pressure refers to sitting systolic pressure nine months after randomisation.

TABLE II -Characteristics of patients according to treatment and thirds of treated diastolic pressure

\begin{tabular}{|c|c|c|c|c|c|c|}
\hline & \multicolumn{3}{|c|}{ Placebo group } & \multicolumn{3}{|c|}{ Active treatment group } \\
\hline & $\begin{array}{c}\text { Lowest } \\
\text { third } \\
(n=119)\end{array}$ & $\begin{array}{c}\text { Middle } \\
\text { third } \\
(\mathrm{n}=92)\end{array}$ & $\begin{array}{c}\begin{array}{c}\text { Highest } \\
\text { third } \\
(n=128)\end{array} \\
\end{array}$ & $\begin{array}{c}\text { Lowest } \\
\text { third } \\
(\mathbf{n}=132)\end{array}$ & $\begin{array}{c}\text { Middle } \\
\text { third } \\
(\mathbf{n}=110)\end{array}$ & $\begin{array}{c}\text { Highest } \\
\text { third } \\
(\mathbf{n}=109)\end{array}$ \\
\hline $\begin{array}{l}\text { No of person years of follow up in double blind study } \\
\text { No }(\%) \text { of men at randomisation } \\
\text { No }(\%) \text { with cardiovascular complications at randomisation } \\
\text { No }(\%) \text { who smoked at randomisation } \\
\text { Mean }(\%) \text { age at randomisation (years) }\end{array}$ & $\begin{array}{c}441 \\
29(24) \\
43(36) \\
17(14) \\
74 \cdot 5(8 \cdot 7)\end{array}$ & $\begin{array}{c}353 \\
35(38) \\
28(30) \\
13(14) \\
71 \cdot 2(6 \cdot 7)\end{array}$ & $\begin{array}{c}417 \\
37(29) \\
44(34) \\
18(14) \\
69 \cdot 3(6 \cdot 8)\end{array}$ & $\begin{array}{c}481 \\
29(22) \\
48(36) \\
28(21) \\
74 \cdot 1(9 \cdot 2)\end{array}$ & $\begin{array}{c}427 \\
39(35) \\
40(36) \\
21(19) \\
70 \cdot 8(6 \cdot 3)\end{array}$ & $\begin{array}{c}443 \\
40(37) \\
36(33) \\
19(17) \\
68 \cdot 2(6 \cdot 3)\end{array}$ \\
\hline \multicolumn{7}{|c|}{ Characteristics during follow up } \\
\hline Extremes of treated diastolic pressure ${ }^{\star}(\mathrm{mm} \mathrm{Hg})$ & $60-90$ & $92-98$ & $100-138$ & $56-84$ & $86-90$ & $92-126$ \\
\hline $\begin{array}{l}\text { Treated systolic/diastolic pressure at middle of third }(\mathrm{mm} \mathrm{Hg}) \\
\text { Mean }(\mathrm{SD}) \text { difference between treated pressure and pressure at } \\
\text { randomisation }(\mathrm{mm} \mathrm{Hg}) \text { : }\end{array}$ & $160 / 85$ & $173 / 95$ & $186 / 108$ & $147 / 78$ & $151 / 88$ & $159 / 98$ \\
\hline Systolic & $-22(19)$ & $-8(16)$ & $4(17)$ & $-38(21)$ & $-30(18)$ & $-22(19)$ \\
\hline Diastolic & $-14(8)$ & $-4(6)$ & $4(9)$ & $-20(8)$ & $-12(6)$ & $-5(8)$ \\
\hline Mean (SD) body weight at 9 months $(\mathrm{kg})$ & $62.5(12 \cdot 9)$ & $67 \cdot 2(11 \cdot 8)$ & $70 \cdot 5(13 \cdot 8)$ & $62 \cdot 8(12 \cdot 3)$ & $65 \cdot 2(11 \cdot 9)$ & $69 \cdot 8(11 \cdot 2)$ \\
\hline Mean (SD) haemoglobin at 1 year $(\mathrm{g} / \mathrm{l})$ & $137(15)$ & $144(12)$ & $146(16)$ & $135(18)$ & $141(13)$ & $146(15)$ \\
\hline No of patients in whom haemoglobin was measured & 96 & 66 & 96 & 100 & 87 & 83 \\
\hline
\end{tabular}

ॠTreated diastolic pressure refers to sitting diastolic pressure nine months after randomisation. 


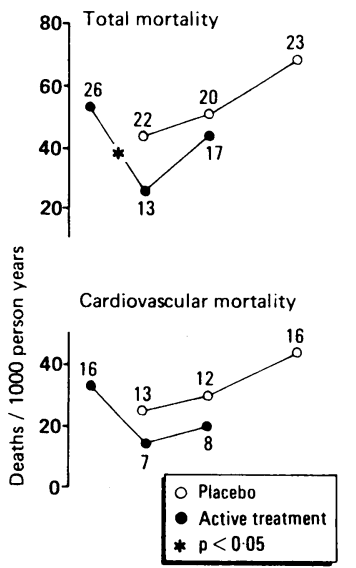

40- Non-cardiovascular mortality
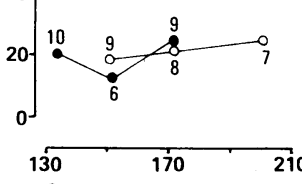

Systolic pressure $(\mathrm{mm} \mathrm{Hg})$

FIG 1-Total, cardiovascular, and non-cardiovascular mortalities adjusted for age and sex in thirds of treated systolic pressure in patients randomised to placebo or active treatment. Figures are numbers of deaths in each third
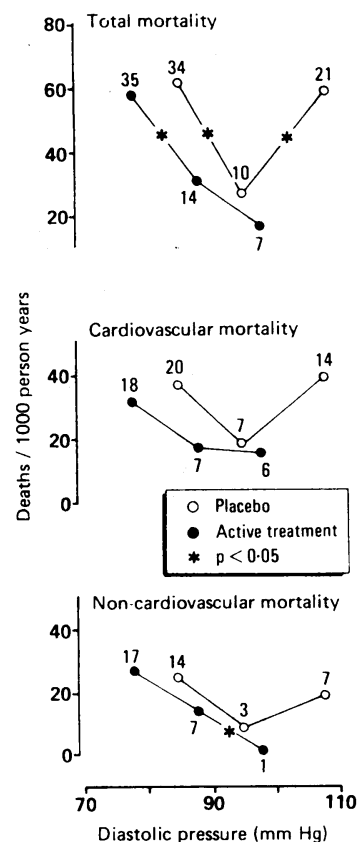

FIG 2-Total, cardiovascular, and non-cardiovascular mortalities adjusted for age and sex in thirds of treated diastolic pressure in patients randomised to placebo or active treatment. Figures are numbers of deaths in each third

\section{Mortality after nine months}

From the visit at nine months until the end of the double blind study 65 patients in the placebo group and 56 in the group taking active treatment died. As the age and sex distributions varied in the thirds of blood pressure (tables I and II) only adjusted rates are presented. The conclusions, however, were not different when the calculations were based on crude rates (number of deaths per person years at risk). For a similar achieved systolic (fig 1) or diastolic (fig 2) blood pressure mortality was lower in those taking active treatment than in those taking placebo.

Mortality in thirds of systolic pressure-In patients taking placebo total, cardiovascular, and non-cardiovascular mortality (fig 1) tended to increase from the lower to the upper third. In patients taking active treatment fewer patients died in the middle than the lowest third $(p<0.05)$. When the three thirds of systolic blood pressure were compared a $U$ shaped relation was apparent between treated systolic pressure and total mortality (fig 1). A similar trend was also observed for cardiovascular and non-cardiovascular mortality.

Mortality in thirds of diastolic pressure-In patients treated with placebo mortality from all causes was lower $(p<0.05)$ in the middle than the two other thirds (fig 2). Cardiovascular and non-cardiovascular mortality showed a similar $U$ shaped tendency. In patients taking active treatment both total $(\mathrm{p}<0.004)$ and non-cardiovascular $(\mathrm{p}<0.007)$ mortality were higher in the lowest than the highest third of blood pressure, and a similar trend was also present for cardiovascular mortality (fig 2).

\section{DETERMINANTS OF MORTALITY}

Cardiovascular complications at randomisation-In general, total and cardiovascular mortality were higher in patients with than in those without cardiovascular complications at randomisation. Cardiovascular complications at randomisation were not more prevalent in the lower thirds of pressure in either treatment group (tables I and II). The trends shown for total and cardiovascular mortality in figures 1 and 2 were similar in patients with and without cardiovascular complications at randomisation.

Fall in diastolic blood pressure-The median fall in diastolic blood pressure from randomisation to nine months later was $4 \%$ in patients taking placebo and $13 \%$ in those taking active treatment. The high total mortality in the lowest thirds of treated diastolic blood pressure (figure 2) was not associated with a greater than median fall in diastolic blood pressure. Indeed, in the lowest third of diastolic blood pressure in patients taking placebo the risk ratio for patients with a greater than median fall in pressure compared with patients

TABLE III - Mean (SD) percentage changes in body weight and haemoglobin concentration during follow up in patients randomised to placebo and active treatment grouped according to thirds of treated systolic and diastolic blood pressures

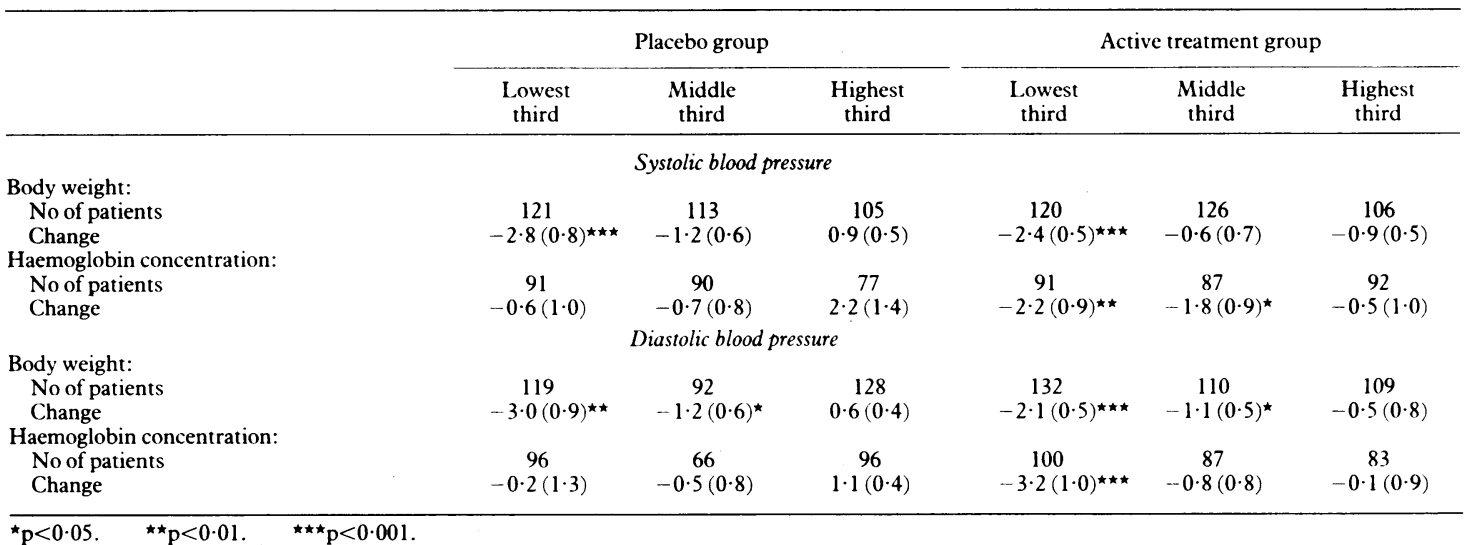

with a smaller fall was $1 \cdot 04(95 \%$ confidence interval $0 \cdot 25$ to $4 \cdot 36)$. Similarly, in the active treatment group the risk ratio was $1.41(0.54$ to $3 \cdot 62)$.

Changes in body weight and haemoglobin concentration-Table III shows the changes in body weight at nine months with double blind treatment and in haemoglobin concentration at one year (haemoglobin concentration was not measured at nine months) as the percentage change in these measurements between these follow up visits and randomisation. The most pronounced decreases in body weight and haemoglobin concentration tended to occur in the patients in the lowest thirds of systolic and diastolic blood pressure during treatment.

\section{Discussion}

In contrast to many,,$^{3.9}$ though not all, ${ }^{17}$ previous studies that have reported a $\mathrm{J}$ shaped relation between analysis was of patients taking placebo as well as of those taking active treatment. We defined treated blood pressure as the pressure nine months after randomisation because in both our treatment groups the average blood pressure decreased until this time, after which no further fall was observed..$^{23}$ Results based on the average of all blood pressure readings were not materially different but were not presented as they may have been biased by non-fatal events such as myocardial infarction and malignant disease developing during treatment. Indeed, these conditions often cause a fall in pressure and are related to subsequent mortality, thereby possibly giving rise to a spuriously high association between a low pressure and a fatal outcome. ${ }^{24}$

In the elderly patients treated with placebo and admitted into the European trial total mortality tended to rise with higher systolic pressure at nine months. In contrast, in the same treatment group the relation between total mortality and diastolic pressure was U shaped with a nadir at around $95 \mathrm{~mm} \mathrm{Hg}$. In the Framingham study a similar pattern - that is, a linear increase in risk with higher systolic pressure and a $\mathrm{J}$ shaped relation between cardiovascular risk and diastolic pressure with a nadir at around $90 \mathrm{~mm} \mathrm{Hg}$ was shown, at least when the effects of logistic smoothing were removed..$^{25}{ }^{26}$ Coope et al who screened 10732 patients aged 60 to 79 , observed a $U$ or J shaped relation of total cardiovascular and coronary mortality with casual systolic and diastolic blood pressures, the lowest incidence being at a systolic pressure of $160-179 \mathrm{~mm} \mathrm{Hg}$ and a diastolic pressure of 80-89 mm Hg. ${ }^{27}$ In a population based study in Sweden there was a $U$ shaped relation between total mortality and both systolic and diastolic pressures in treated blood pressure and mortality the present

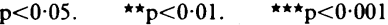


subjects aged 40 to 69 , while in those aged 70 and over a U shaped curve was seen only for diastolic pressure. ${ }^{28} 29$ The relation between diastolic pressure and mortality is certainly more complex than a linear increase with rising pressure. ${ }^{25-30}$

In the actively treated patients in this trial the relation between total mortality and the treated systolic pressure was $U$ shaped with a nadir at around $150 \mathrm{~mm} \mathrm{Hg}$, whereas total mortality increased gradually with decreasing diastolic pressure. Previous studies, which were mostly retrospective and not placebo controlled, focused attention on the possible deleterious effects of an exaggerated reduction in blood pressure induced by drugs, especially on the incidence of coronary events. ${ }^{3.7}$ In some studies these conclusions were based on the average of all pressure readings throughout follow up ${ }^{5.7}$ or on small differences with wide confidence intervals in the number of deaths between subgroups of treated pressure. ${ }^{56}$

Although an exaggerated reduction in blood pressure may be harmful, perhaps by impeding the coronary or cerebral circulation, ${ }^{1}{ }^{11131}$ the present findings suggest that an excessive drug induced reduction in blood pressure is not the only mechanism underlying the $\mathrm{J}$ curve. ${ }^{3.9}$ Indeed, in the present study (fig 2) and in earlier reports by Coope and Warrender ${ }^{1718}$ an increased mortality was also noticed in patients with a low diastolic blood pressure taking placebo. An exaggerated drug induced reduction in blood pressure is likely to be most harmful in patients with cardiovascular complications, in whom the coronary and cerebral circulations are already compromised. In the present study, however, cardiovascular complications at entry did not alter the relation between mortality and treated pressure. This finding is at variance with the reports of Cruickshank et al, who showed that the $\mathrm{J}$ shaped relation was confined to hypertensive patients with complications of atherosclerosis. $^{56}$

Among the patients in the lowest thirds of treated diastolic pressure mortality was similar regardless of whether the fall in diastolic pressure after randomisation exceeded the median fall. Furthermore, not only cardiovascular mortality, which is likely to be adversely affected by an excessive reduction in blood pressure, but also non-cardiovascular mortality followed a pattern similar to that of total mortality (figs 1 and 2). Finally, patients with the lowest pressure during randomised treatment also experienced the greatest falls in body weight and haemoglobin concentration during the first year of follow up (table III). This could be related to some deterioration of general health.

In conclusion, the present analysis showed that in elderly patients with hypertension given active treatment total mortality had a $U$ shaped relation with treated systolic pressure and an inverse association with treated diastolic pressure. The U curve between mortality and diastolic pressure in the patients taking placebo indicates that the increased mortality in the lower thirds of the actively treated patients may not be drug induced. This increased mortality could also be the expression of some deterioration in general health, as suggested by the decreases in body weight and haemoglobin concentration.

We thank the patients who took part in the trial and Mrs V Mariën, Mrs L Thijs, Mrs Y Toremans, and Mrs S Van Hulle for clerical and technical help.

The trial was coordinated by A Amery, Leuven, and A De Schaepdryver, Ghent, Belgium. The steering committee comprised A Amery, A De Schaepdryver, C Dollery, J V Joossens, and T Strasser. The advisers were E Freis, F Gross (deceased), M Healy, S Hoobler, P Milliez, and J Willems. The trial was carried out in consultation with the World Health Organisation and supported by the Belgian National
Research Foundation and the Belgian Hypertension Committee through a grant from Merck Sharp and Dohme and Smith, Kline and French. These companies prepared Aldomet tablets (500 mg methyldopa) and Dyazide capsules (25 mg hydrochlorothiazide and $50 \mathrm{mg}$ triamterene) and matching placebos. The drugs were processed under the supervision of A De Maesschalck with the advice of G Van Herpe. Yearly meetings were sponsored by the European Economic Community, Imperial Chemical Industries, and Astra; J Vanhollenbeke, of Boehringer Pharma, Belgium, collaborated in performing the quality control.

The following centres collaborated in the trial: University Hospital Haukeland, Bergen, Norway-P Lund-Johansen, O J Ohm, P Omvik; North Karelia Project, Helsinki, Finland-A Alasoini, A Koistinen, A Nissinen, P Puska, J Tuomilehto, R Varis; Zuidersickenhuis, Rotterdam, The Netherlands-W Birkenhäger, $\mathbf{P}$ de Leeuw, $\mathrm{P}$ Willemse; Victoria Geriatric Unit, Glasgow, Scotland-K Beard, J L C Dall, J P R MacFarlane (deceased), B O Williams; Aberdeen Royal Infirmary, Aberdeen, Scotland-T A Jeffers, J C Petrie, O J Robb, J Webster; Royal College of Surgeons, Dublin, Ireland -M Laher, P McCormack, F Meagher, E O'Brien, W O'Callaghan, K O'Malley; Hammersmith Hospital, London, England-C J Bulpitt, C Dollery, A E Fletcher, P Lewis, M Murphy; St Fohn's Hospital, London, England-R C Hamdy, N H Perera; St Charles's Hospital, London, England-X Chellappah, J Morris, A I Suchett-Kaye; University Hospital, Cologne, West Germany-H Feltkamp, A Konrads, U Laaser, K Meurer; University Hospital Gasthuisberg, Leuven, Belgium -A Amery, R Fagard, J Hellemans (deceased); J V Joossens, P Lijnen, W Pelemans, J Staessen, L Thijs, R Van Hoof; University Hospital, Ghent, Belgium-M Bogaert, D Clement, A De Schaepdryver; Geriatric Hospital Le Valdor, Liège, Belgium-P Brixko, A Ernould, A Mutsers; University Hospital St Luc, Brussels, Belgium-J F De Plaen, Ch van Ypersele; Medical Centre for House Physicians, Leuven, Belgium-M Deruyttere; Charles Foix Hospital, Ivry, France -P Berthaux, F Forette, J F Henry; Centre of Clinical Physiology and Hypertension, Milan, Italy-G Leonetti, $\mathrm{X}$ Tammaro, L Terzoli, A Zanchetti; University Hospital Santa Maria, Lisbon, Portugal-F de Padua, J Forte, J M PereiraMiguel.

1 Cruickshank JM. Coronary flow reserve and the J-curve relation between diastolic blood pressure and myocardial infarction. $B r$ Med $\mathcal{f}$ 1988;297: $1227-30$

2 Beevers DG. Overtreating hypertension. Br Med f 1988;297:1212.

3 Stewart IMcDG. Relation of reduction in pressure to first myocardial infarction in patients receiving treatment for severe hypertension. Lancet $1979 ; \mathrm{i}: 861-5$.

4 Stewart IMcDG. $\beta$-Adrenoceptor blockade and the incidence of myocardial infarction during treatment of severe hypertension. $\mathrm{Br} \mathcal{f}$ Clin Pharmacol 1982;13:91-3.

5 Cruickshank JM, Thorp JP, Zacharias FJ. Benefits and potential harm of lowering high blood pressure. Lancet 1987;i:581-4.

6 Cruickshank JM, Pennert K, Sörman AE, et al. Low mortality from all causes including myocardial infarction in well controlled hypertensives treated including myocardial infarction in well controlled hypertensives treated
with a beta-blocker plus other antihypertensives. $\mathcal{f}$ Hypertens 1987;5: with a

7 Samuelsson O, Wilhelmsen L, Andersson OK, et al. Cardiovascular morbidity in relation to change in blood pressure and serum cholesterol levels in treated hypertension: results from the primary prevention trial in Göteborg, Sweden. FAMA 1987;258:1768-76.

8 Waller PC, Isles CG, Lever AF, et al. Does therapeutic reduction of diastolic blood pressure cause death from coronary heart disease? Journal of Human Hypertension 1988;2:7-10.

9 Fletcher AE, Beevers DG, Bulpitt CJ, et al. The relationship between a low treated blood pressure and IHD mortality: a report from the DHSS hypertension care computing project (DHCCP). Fournal of Human Hypertension 1988;2:11-5.

10 Green KG. The role of hypertension and downward changes of blood pressure in the genesis of coronary atherosclerosis and acute myocardial ischemic attacks. Am Heart f 1982;103:579-82.

11 Strandgaard S, Haunsø S. Why does antihypertensive treatment prevent stroke but not myocardial infarction? Lancet 1987;ii:658-61.

12 Management Committee. The Australian trial in mild hypertension. Lancet 1980;i:1261-7.

13 Management Committee of the Australian Therapeutic Trial in Mild Hypertension. Untreated mild hypertension. Lancet 1982;i:185-91.

14 IPPPSH Collaborative Group. Cardiovascular risk and risk factors in a randomised trial of treatment based on the beta-blocker oxprenolol: the international prospective primary prevention study in hypertension (IPPPSH). I Hypertens 1985;3:379-92.

15 Medical Research Council Working Party. MRC trial of treatment of mild hypertension: principal results. Br Med f 1985;291:97-104.

16 Miall WE, Greenberg G. Mild hypertension: is there pressure to treat? Cambridge: Cambridge University Press, 1987:101-8.

17 Coope J, Warrender TS. Randomised trial of treatment of hypertension in elderly patients in primary care. $\mathrm{Br} \mathrm{Med} \mathcal{F}$ 1986;293:1145-51

18 Coope J, Warrender TS. Lowering blood pressure. Lancet 1987; ;: 1380

18 Coope J, Warrender TS. Lowering blood pressure. Lancet 1987;i:1380.
19 European Working Party on High blood pressure in the Elderly. An European Working Party on High blood pressure in the Elderly. An
international trial of antihypertensive therapy in elderly patients: objectives, international trial of antihypertensive therapy in elderly patients: objectives,
protocol and organization. Arch Int Pharmacodyn Ther 1985;275:300-34. 
20 Amery A, Birkenhäger W, Brixko $\mathrm{P}$, et al. Mortality and morbidity results from the European working party on high blood pressure in the elderly trial. Lancet 1985; ;:1349-54.

21 Amery A, Birkenhäger W, Brixko P, et al. Efficacy of antihypertensive drug treatment according to age, sex, blood pressure and previous cardiovascular treatment according age, sex, blod press 686 ;ii:589-92.

22 Kahn HA. An introduction to epidemiologic methods. New York: Oxford University Press, 1983.

23 Amery A, De Schaepdryver A. (For the European Working Party on High Amery A, De Schaepdryver A. (For the European Working Party on High
blood pressure in the Elderly.) Antihypertensive therapy in patients above age sixty. In: Onesti G, Kim KE, eds. Hypertension in the young and old. New York: Grune and Stratton, 1981:315-26.

24 Bulpitt CJ, Beevers DG, Butler A, et al. Treated pressure rather than pretreatment predicts survival in hypertensive patients. A report from the DHSS hypertension care computing project (DHCCP). F Hypertens 1988;6: 627-32.

25 Kannel WB. Role of blood pressure in cardiovascular disease: the Framingham study. Angiology 1975;26:1-14.
26 Anderson TW. Re-examination of some of the Framingham blood pressure data. Lancet 1978;ii:1139-41.

27 Coope J, Warrender TS, McPherson K. The prognostic significance of blood pressure in the elderly. Fournal of Human Hypertension 1988;2:79-88.

28 Lindholm L, Lanke J, Bengtsson B, et al. Both high and low blood pressure risk indicators of death in middle-aged males. Isotonic regression of bured

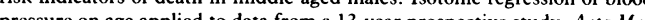
pressure on age applied to data from a 13-year prospective study. Acta Med

29 Lindholm L, Lanke J, Bengtsson B. U-shaped association between mortality and blood pressure in a thirteen-year prospective study. Family Practice 1986;3:3-8.

30 Miall WE, Brennan PJ. Hypertension in the elderly: the south Wales study In: Onesti G, Kim KE, eds. Hypertension in the young and very old. New York: Grune and Stratton, 1981:227-83.

31 Anonymous. How far to lower blood pressure? [Editorial.] Lancet 1987;ii $251-2$.

(Accepted 5 April 1989)

\section{Prevalence and diagnosis of chronic respiratory symptoms in adults}

Peter Littlejohns, Shah Ebrahim, Ross Anderson

\begin{abstract}
Objective-To investigate the prevalence and diagnosis of chronic respiratory disease in adults.

Design-Screening questionnaire was sent to all patients aged 40-70 on the register of a group general practice; those responding positively were sent a detailed questionnaire and invited for assessment of respiratory function by forced expiratory volume in one second, forced vital capacity, peak flow rate, and reversibility studies with a $\beta$ adrenergic inhaler.
\end{abstract}

Setting-Group general practice in south west London.

Results-Of 2387 patients aged 40-70, 1444 completed a screening questionnaire. Of the 509 patients who reported cough, phlegm, wheeze, or shortness of breath, 324 responded to a detailed questionnaire, 256 of whom had simple respiratory function assessed. Chronic bronchitis affected $106(17 \%)$ men and $58(7 \%)$ women, and wheeze occurring at least once a week affected $60(9 \%)$ men and $20(3 \%)$ women. Only a half to a third of patients had received a diagnostic label of chronic bronchitis or asthma for their symptoms. There was considerable clinical and physiological similarity (including reversibility of the airways) between patients labelled as having asthma and having chronic bronchitis. A label of asthma was used more often for patients of social classes I and II.

Conclusions-Comparison with prevalence surveys carried out in the 1950 s showed that respiratory symptoms are as common now as then, but the risk of disabling chronic bronchitis has fallen, more among men than women, probably because of their reduced smoking. Changes in diagnostic fashion, together with increased detection, may have contributed to the upward trend in reported morbidity from asthma over the past 30 years.

Department of Clinical Epidemiology and Social Medicine, St George's Hospital Medical School, London SW17 0RE

Peter Littlejohns, MFCM, lecturer

Shah Ebrahim, DM, Wellcome Trust lecturer Ross Anderson, $\mathrm{MD}$, professor

Correspondence to: $\mathrm{Dr}$ Littlejohns.

BrMed f 1989;298:1556-60 diagnosis, management, and presentation of patients.

As asthma and chronic bronchitis in adults share some important symptomatic and pathophysiological features, diagnostic transfer may also contribute to these trends. It has been reported in studies from America, ${ }^{89}$ but its extent and implications have not been examined in the general population in the United Kingdom. We investigated the prevalence of chronic respiratory symptoms and their associated diagnostic labels and medical care in a general adult population and examined the extent to which illnesses labelled as asthma or chronic bronchitis differed in their clinical and physiological features and what other factors were associated with the acquisition of these labels. We also compared their prevalences with those found in similar studies that were carried out in the $1950 \mathrm{~s} .{ }^{10-14}$

\section{Methods}

The age-sex register of a group general practice in south west London was used to identify men and women aged 40-70. They were sent a previously validated screening questionnaire that inquired about coughing on winter mornings, phlegm on winter mornings, wheezing or whistling in the chest, shortness of breath on washing and dressing, and distance walked on the level before becoming short of breath.' $\mathrm{Up}$ to two reminders were sent. Patients who responded positively to at least one question were sent a detailed respiratory questionnaire that included questions on chronic bronchitis from the Medical Research Council's respiratory questionnaire. ${ }^{16}$ Questions were also asked about the frequency and duration of symptoms over the past year; walking capability on the level, on hills, and on stairs; and the effect of the respiratory illness on everyday life and activities. Subjects were asked to record what they considered to be the diagnosis of their condition. The diagnosis recorded in the general practitioner's case notes was also obtained.

All subjects who completed the detailed questionnaire were invited to the surgery for tests of respiratory function. Forced expiratory volume in one second, forced vital capacity, and peak expiratory flow rate were measured with a McDermott spirometer, which was calibrated daily; the best of five attempts was recorded. Height was measured to the nearest centimetre. Reversibility with a $\beta$ adrenergic inhaler was assessed 10 minutes after inhalation of $1 \mathrm{mg}$ of terbutaline (four puffs) from a Nebuhaler (Astra 